\title{
Objetivos, discursos y protagonistas del Congreso Cultural de La Habana (1968)
}

\author{
Objectives, discourses and protagonists of \\ the Havana Cultural Congress (1968) \\ VALERIA GONZÁLEZ LAGE ${ }^{1}$ \\ Universidade de Santiago de Compostela \\ valeria.gonzalez@usc.es \\ Orcid: https://orcid.org/0000-0002-9876-4740 \\ http://dx.doi.org/10.15304/sm.31.5993
}

\section{RESUMEN}

Este artículo reflexiona sobre el Congreso Cultural celebrado en La Habana en enero de 1968. En ese evento más de cuatrocientos intelectuales de todo el mundo fueron convocados para debatir los efectos del colonialismo y el neocolonialismo en el desarrollo de los pueblos y la responsabilidad de los intelectuales ante la penetración cultural del imperialismo y el avance de las luchas de liberación. El texto se centrará en el contexto del Congreso, motivaciones para su celebración e ideas formuladas durante sus sesiones.

Palabras Clave: Congreso Cultural; intelectuales; Revolución; imperialismo; Cuba.

\begin{abstract}
This article ponders on the Cultural Congress held in Havana in January 1968. In that event, more than four hundred intellectuals from all over the world were summoned to discuss the effects of colonialism and neocolonialism on the development of peoples and the responsibility of intellectuals in the face of the cultural penetration of imperialism, the overcoming of underdevelopment and the advance of liberation struggles. The text will focus on the context of the congress, motivations for its celebration and ideas formulated during its sessions.
\end{abstract}

Keywords: Cultural Congress; intellectuals; Revolution; imperialism; Cuba.

1 Trabajo parte de una tesis doctoral en curso respaldada por el Programa FPU (Ministerio de Educación, Cultura y Deporte-España). Realizado en el marco del Proyecto HAR2016-77828-R (Ministerio de Economía, Industria y Competitividad-España y Fondo Europeo de Desarrollo Regional) y del Grupo HistAmérica-Universidad de Santiago de Compostela (GPC-ED431B 2017/36 Xunta de Galicia). 
«Los imperialistas, ¿qué dirán, qué pensarán? Dirán tal vez que esto es un Viet Nam en el campo de la cultura; dirán que han empezado a aparecer las guerrillas entre los trabajadores intelectuales» (CCH, 1968: 73). Así clausuraba Fidel Castro el Congreso Cultural dado en La Habana entre los días 4 y 12 de enero de 1968. Previamente se había celebrado a nivel nacional un Seminario Preparatorio entre octubre y noviembre de 1967. Los lazos de escritores con la Revolución no eran nuevos. Numerosos intelectuales habían visitado la isla atraídos por un proceso de transformación social que marcaba importantes rupturas con los modelos de izquierda tradicional, incluido el campo cultural (De la Nuez, 2006; Artaraz, 2011; Rojas, 2016). La novedad en 1968 radicaba en la conjunción de objetivos entre un sector intelectual internacional y las fuerzas revolucionarias que, como Cuba, pretendían elevar al sur global como contrapeso a la lógica de la Guerra Fría.

Este artículo conecta con la definición que en los últimos años se ha elaborado sobre la existencia de una oleada de movilización política de Nueva Izquierda a partir de los años sesenta caracterizada por haber compartido un marco ideológico común: aspiraciones de transformación social, apertura de nuevos repertorios de acción, crítica a la práctica y la teoría manejadas por la izquierda tradicional, búsqueda de nuevos sujetos revolucionarios, oposición a cualquier dominación política, económica, racial y cultural y la renovación de los códigos morales que servían de marco de interacción social (Katsiaficas, 1987; Martín Álvarez y Rey Tristán, 2012). El campo intelectual fue efectivamente consumidor, creador y difusor de ese ethos de cambio, si bien con particularidades para cada caso nacional (Terán, 1993; Kenny, 1995; Artaraz, 2011; Kalter, 2016). Distanciados de la izquierda tradicional tras el XX Congreso del Partido Comunista de la Unión Soviética y la crisis de Hungría, los intelectuales encontraron nuevos retos en su agenda ante las revoluciones de Cuba, Argelia o Vietnam. Durante esa «época» emergió la noción del intelectual ligado a la izquierda, comprometido con las causas progresistas y respaldado por su impacto en la dimensión pública (Gilman, 2003).

El Congreso Cultural apenas ha sido objeto de investigación. Recibió atención por parte del ensayista cubano Acosta de Arriba desde el punto de vista de su organización (Acosta, 2015) y, recientemente, Candiano (2018a) aportó un análisis de discurso a partir de las declaraciones finales y algunas de las ponencias. Más allá de estos trabajos, solo es referido brevemente en la producción sobre la intelectualidad latinoamericana (Gilman, 2003; Franco, 2003), la política cultural de Cuba (Gallardo-Saborido, 2009; Fornet, 2013) o su relación con la nueva izquierda europea (Artaraz, 2011).

Para cubrir el vacío, hemos recurrido a reportajes de la época ${ }^{3}$, los testimonios de algunos asistentes (Aub, 1969; Salkey, 1971; Karol, 1972; Otero, 1999; Franqui, 2006;

2 "El Congreso olvidado" es una síntesis de un libro sobre el Congreso Cultural en proceso de edición. Fue recogido en MINCULT (2015).

3 Le Nouvel Observateur, París: M. Bosquet, "Castro abre un nuevo frente", 24/01/1968; Revista de la BNJM, La Habana: J. Pérez, "El Congreso Cultural de La Habana”, 59, 1968, p. 108-127; Monthly Review, Nueva York: J. Higgins, “Cuba's Cultural Congress”, 19 (10), marzo 1968, p. 21-28. 
Pogolotti, 2011), las compilaciones de los documentos principales (CCH, ca. 1967; CCH, 1968) y la antología digital que elaboró el Ministerio de Cultura de Cuba sobre el evento (MINCULT, 2015).

Este texto enfoca al Congreso Cultural desde el punto de vista de su génesis y de la pluralidad de discursos que acogió. Su objetivo es tratar de desentrañar las posibles motivaciones que incentivaron su convocatoria, identificar los principales hitos en su organización, sus protagonistas y ofrecer un balance de los debates que se desarrollaron en sus sesiones. Por cuestión de espacio no se presta atención a los sucesos posteriores, ya examinados por otros autores (Fornet, 2007; De la Torre, 2008; Fornet, 2013).

El trabajo se divide en tres bloques. El primero considera el origen del Congreso Cultural, sus promotores y los factores que contribuyeron a su celebración. El segundo se centra en el Seminario Nacional Preparatorio celebrado entre octubre y noviembre de 1967 como antesala del Congreso, teniendo como foco los temas generales tratados en el Seminario y, especialmente, las principales contradicciones suscitadas. El tercer bloque se ocupa del Congreso Cultural. En él se pone el acento en el cómputo de los delegados de las diferentes áreas geopolíticas y el examen de los temas más destacados en cada comisión, los documentos colectivos aprobados y el discurso final de Fidel Castro.

\section{LOS PROLEGÓMENOS DEL CONGRESO}

Una vez declarado el carácter socialista de la Revolución cubana, se había abierto un período de debate acerca de qué modelo acoger para la isla. Al cruce de propuestas sobre la planificación económica y los incentivos materiales se le añadieron las discusiones sobre el realismo socialista y la enseñanza del marxismo-leninismo (Pogolotti, 2007). 1965 anunciaba respuestas. En el Segundo Seminario Económico de Solidaridad Afroasiática celebrado en Argel, Ernesto Guevara conminó a los países socialistas a tender su ayuda a las luchas de liberación. En "El Socialismo y el hombre en Cuba" el argentino ponía también punto final, al menos temporalmente, a las polémicas en el campo cultural con el rechazo del realismo socialista y el reclamo a la creación de una verdadera intelectualidad orgánica de la Revolución. Por fin, en octubre de 1965, Castro anunciaba la creación del Partido Comunista de Cuba, la construcción del comunismo y el socialismo simultáneamente y el trazado de una línea propia.

Aislado regionalmente desde 1964 -sólo mantenía relaciones con México- y contrario a la coexistencia pacífica propugnada por el socialismo del Este, el Gobierno cubano abrazó durante los años posteriores un claro proyecto internacionalista contra el imperialismo. Esta política se tradujo en la promoción pública de las luchas de liberación en el sur y los intentos por conquistar apoyos entre la Nueva Izquierda que nacía en diversos puntos. El tercer mundo parecía representar la comunidad real e imaginada que permitiría esquivar a las dos superpotencias (Kapcia, 2008: 122). 
El primer foro con carácter unificador tuvo lugar en 1966 con la celebración de la Conferencia Tricontinental, reunión de las fuerzas revolucionarias de África, Asia y América Latina para debatir estrategias y tácticas en la toma de poder. Su secuela a escala regional sería la Organización Latinoamericana de Solidaridad (OLAS), que en 1967 intentó institucionalizar la guerrilla como principal estrategia de lucha antiimperialista ${ }^{4}$.

Hacia 1968 los diferendos entre la isla y los soviéticos se agudizaron. Dos días antes de iniciarse el Congreso, Fidel Castro comunicó que el Gobierno ruso reduciría el abastecimiento de petróleo a la isla (Castro, 1968). Los días 24, 25 y 26 de enero se reunía el Comité Central del Partido Comunista de Cuba para juzgar la llamada «microfacción». Esta corriente, vinculada a antiguos sectores del Partido Socialista Popular (el comunismo cubano tradicional), habría manifestado opiniones contrarias a la línea política del partido desde 1966 y habría intentado influir en personalidades nacionales y del bloque socialista para reconducir el rumbo de Cuba (CCPCC, 1968).

Inserto en este marco de radicalización, el proyecto del Congreso Cultural nació a principios de 1967. En su organización se diferencian tres hitos: la reunión del Comité de Colaboración de la revista Casa de las Américas en enero de 1967, que promovía una reunión tricontinental de intelectuales; la creación en verano del Comité Nacional Preparatorio, encargado de gestionar las invitaciones y orientar la temática del evento; y la celebración del Seminario Nacional Preparatorio entre octubre y noviembre de 1967. Nuestro interés en las próximas páginas será indagar en la idea original que propuso Casa de las Américas, en su realización práctica y, finalmente, en el Seminarios.

El proyecto del Congreso se originó en el entorno de Casa de las Américas. Esta institución se había creado en 1959 para reforzar los lazos culturales de Cuba con América Latina y el Caribe. Dirigida por Haydée Santamaría -participante en la insurrección contra Fulgencio Batista- creaba y difundía conocimiento, principalmente a través de su publicación Casa de las Américas. Según los testimonios, la intención de realizar un encuentro de intelectuales se gestó en la reunión del Comité de Colaboración de la revista, celebrada entre el 5 y el 8 de enero de $1967^{\circ}$. Al finalizar el encuentro aprobaron una declaración en la que abrían perspectivas comunes de lucha contra el imperialismo en el plano intelectual. El texto categorizaba una nueva situación en el mundo, signada por la ofensiva norteamericana en el panorama cultural y ejemplificada en los Planes Camelot, Simpático, Numismático o las actividades del Congreso por la Libertad de la Cultura.

4 Cuba mantenía contactos con grupos revolucionarios desde inicios de 1960. Véase Kruijt (2017: 84120).

5 Sobre el Comité Nacional Preparatorio véase Acosta (2015). Por cuestión de espacio no se trata en esta ocasión.

6 Entrevista a Roberto Fernández Retamar, La Habana, 28/11/2018. Alfredo Guevara (director del Instituto Cubano del Arte e Industria Cinematográficos) da la misma versión en carta a Glauber Rocha (10/08/1967, en Guevara y Rocha, 2002: 64-65). Fernández Retamar dirigía la revista Casa de las Américas desde su número 30 (mayo-junio de 1965) y fue miembro del Comité Nacional Preparatorio del Congreso Cultural. 
Por eso, y pese a las legítimas diferencias de opinión que puedan existir entre los escritores de izquierda, tenemos la convicción de que todos ellos sienten la necesidad de entablar un diálogo lo más abierto y amplio posible con objeto de articular los principios que permitan hacer frente a esa ofensiva y establecer un denominador común de acción. [...] concluimos con un llamamiento a los intelectuales de los países subdesarrollados... ${ }^{7}$

Esta propuesta se nutría del empuje heredado de la Conferencia Tricontinental y, especialmente, de las resoluciones adoptadas por su Comisión Social y Cultural en relación con la creación de un frente activo contra la penetración cultural en los países subdesarrollados (OSPAAAL, 1966: 127-140). Sin embargo, el carácter tricontinental del Congreso se vería modificado al ampliarse la convocatoria a los países desarrollados. Según Fernández Retamar, el viraje se decidió en la cena que cerró el Encuentro con Rubén Darío planificado por Casa de las Américas (Varadero, 16-22 de enero de 1967):

Los integrantes del comité de colaboración de la revista Casa y algunos invitados más asistimos, en el Museo de Artes Decorativas de La Habana, a una larga cena con el compañero Fidel [...]. La organización del Congreso salió de las manos de la Casa de las Américas y fue asumida por el Ministerio de Educación (no existía todavía el Ministerio de Cultura), a cuyo frente se hallaba el compañero José Llanusa, y cambió de horizonte. Dejó de ser una reunión de intelectuales del Tercer Mundo para abarcar a intelectuales del planeta todo, en particular, según creo recordar, del mundo occidental (Acosta, 2015: 12-13).

Este cambio en la organización y su trasvase al Ministerio de Educación obedecería a razones logísticas, pues el carácter mundial que finalmente adquirió el evento excedía la capacidad de recursos de Casa de las Américas ${ }^{8}$. En el Seminario Nacional Preparatorio, José Llanusa, a la sazón ministro de educación, aportó otra visión sobre el origen del Congreso. Afirmó que su celebración se debía a una vieja aspiración de Fidel Castro de «unir a intelectuales de todas partes del mundo en una gran asamblea» (CCH, ca. 1967: 3). Los testimonios disponibles indican, por tanto, que fue Casa de las Américas la promotora inicial de una conferencia tricontinental y que su ultimación fue fruto de un intercambio entre intelectuales cubanos y el Gobierno. A raíz de estas conversaciones, se decidió que el evento estaría abierto a los países desarrollados y, por orientación de Fidel $(\mathrm{CCH}$, ca. 1967: 3-4), que se invitaría a escritores, artistas, científicos y técnicos.

Decidida la dimensión que tendría el Congreso, hacia el verano de 1967 se constituyó el Comité Nacional Preparatorio integrado por 64 personalidades de distintas insti-

7 Casa de Las Américas, La Habana: Comité de Colaboración de Casa de las Américas, "Declaración del Comité de Colaboración de la revista Casa de las Américas”, 41, marzo-abril 1967, p. 2-4.

8 Entrevista de M. Berrios y J. Jakobson a Fernández Retamar, La Habana, abril 2014 (MINCULT, 2015). 
tuciones cubanas ${ }^{9}$. Entre sus tareas estaban las de conformar las listas de los delegados al Seminario y al Congreso, estructurar los temas de las comisiones de trabajo y enviar con antelación el reglamento y material bibliográfico a cada uno de los participantes cubanos y extranjeros (Acosta, 2015: 19). Para la ocasión, las instituciones cubanas se encargaron de aportar listados de bibliografía ${ }^{10}$.

Respecto a los factores que contribuyeron a la celebración del evento, algunos escritores cubanos lo interpretaron como apoyatura al foco que estaba intentando crear Che Guevara en Bolivia (Campuzano, 2001: 48). Aunque su muerte en octubre de 1967 frustraría esta aspiración, el evento se habría propuesto como una cobertura superestructural a la práctica revolucionaria en curso, una «suerte de caja de resonancia para lo que estaba haciendo el Che» ${ }^{11}$. En resumen, perseguía estructurar una «retórica de cambio optimista» (Gamson y Meyer, 1999: 405-406) que presentase la acción como deseable y hasta impostergable y la revistiese de legitimidad en función del equilibrio existente entre agravios-amenazas y las alternativas propuestas como solución. La intelectualidad aportaba su reflexión teórica acerca del nexo entre subdesarrollo e imperialismo, práctica social y conciencia individual o cómo incorporar a la cultura en un proceso revolucionario. A la par, la demostración pública del apoyo intelectual a las metas del Congreso secundaba la causa internacionalista cubana.

Por otro lado, una mirada a las revistas nacionales de la época evidencia la preocupación que existía por determinar el papel del intelectual en un proceso revolucionario: en marzo-abril de 1966, Casa de las Américas publicó una encuesta realizada por Carlos Núñez a participantes en la Conferencia Tricontinental acerca de la responsabilidad intelectual en los movimientos de liberación; a fines de año la misma revista difundió una mesa redonda emitida por Radio Habana Cuba sobre la penetración del imperialismo yanqui en América Latina; en enero-febrero de 1967 salía a la luz el ensayo "Hacia una intelectualidad revolucionaria en Cuba" de Fernández Retamar ${ }^{12}$. Podemos decir con Candiano (2018b) que fueron antecedentes del Congreso, indicios de un afán por ubicar el compromiso intelectual a partir de la práctica social de la Revolución.

9 Entre ellos: Fernández Retamar, director de Casa de las Américas; Alfredo Guevara, director del Instituto de Arte e Industria Cinematográficos; Nicolás Guillén, presidente de la Unión de Escritores y Artistas de Cuba; Lisandro Otero del Consejo Nacional de Cultura; Rolando Rodríguez, director del Instituto Cubano del Libro; Jorge Serguera, presidente del Instituto Cubano de Radio y Televisión o Jaime Crombet, dirigente de la Unión de Jóvenes Comunistas. El presidente fue José Llanusa Gobel, ministro de educación.

10 Casa de las Américas, La Habana, Archivo Vertical, carpeta Congreso Cultural de La Habana, sección Casa y Cultura, inventario C-0570: Casa de las Américas. Bibliografía para el Seminario del Congreso Cultural de La Habana. Véase también CNC (1967).

11 Entrevista a Roberto Fernández Retamar, La Habana, 28/11/2018.

12 Casa de las Américas: C. Núñez, "El papel del intelectual en los procesos de liberación”, 35, marzoabril 1966, p. 84-99; R. Fernández Retamar, E. Desnoes, L. Otero y A. Fornet, "Sobre la penetración del imperialismo yanqui en América Latina", 39, noviembre-diciembre 1966, p. 133-139; R. Fernández Retamar, "Hacia una intelectualidad revolucionaria en Cuba", 40, febrero 1967, p. 4-18. 
En esos momentos, además, estaba en proceso la estructuración de una Comunidad Latinoamericana de Escritores. Entre el 21 y el 30 de enero de 1965 se había realizado en Génova un encuentro sobre cultura de América Latina donde se había impulsado la creación de una comunidad intelectual en la región, cuya reglamentación quedaba pospuesta para futuras reuniones ${ }^{13}$. Los cubanos habían recibido con agrado esta iniciativa ${ }^{14}$. Fueron las desavenencias suscitadas en 1966 a raíz de la polémica Cuba-Pablo Neruda y, sobre todo, el caso Mundo Nuevo, las que modificaron esta perspectiva y enrarecieron el clima comunitario $^{15}$. Aunque no son nuestro objetivo los debates en torno a la comunidad latinoamericana, cabe mencionarlos como factores que contribuyeron a deslindar posiciones en la intelectualidad de la región (Mudrovcic, 1997; Gilman, 2003: 130-142; Alburquerque, 2011: 259-276). Esta ruptura quedó explicitada durante el Segundo Congreso de Escritores (México), celebrado en marzo de 1967. En este foro, un grupo de escritores, incluida la delegación cubana, leyeron la "Declaración de los 20", por la que rechazaban participar en una agrupación de intelectuales construida sin unidad de actitudes ante la emancipación latinoamericana y concluían que no se podía pretender que un escritor de izquierda integrase la misma comunidad que otro de militancia proimperialista u omiso frente «a los desmanes del enemigo» ${ }^{16}$.

Cuando el Comité de Colaboración de Casa propuso un encuentro tricontinental en enero de 1967, además de una autodefinición en cuanto a responsabilidad con las luchas de liberación, se esperaba una aclaración del compromiso comunitario latinoamericano. Dicho de modo simplista, se dibujaban los límites del bando cubano. A partir de esta perspectiva se entiende que al Congreso hubieran sido invitadas únicamente figuras signadas por su progresismo y sin antecedentes de colaboración con el imperialismo ${ }^{17}$.

Por último, la reunión confería a la Revolución una oportunidad de apertura al mundo y exhibición de los logros alcanzados hasta ese momento. Existían precedentes que habían servido a este propósito. En el verano de 1967 se había programado el Salón de Mayo, ocasión en la que invitados extranjeros se admiraron ante lo que captaron como libertad artística y asimilación de los movimientos vanguardistas (Acosta, 2013: 32-40). El Congreso Cultural podía tener de nuevo atractivo para esta causa. En el Seminario Nacional Preparatorio, José Llanusa enfatizó que se esperaba una reafirmación del movimiento de solidaridad hacia la isla (CCH, ca. 1967: 4). Por este motivo instaba a pro-

13 Con este objetivo se celebrarían: el Primer Congreso de la Comunidad Cultural del continente, Arica, Chile (enero-febrero 1966); el Segundo Congreso Latinoamericano de Escritores, México (marzo 1967); y el Encuentro Latinoamericano de Escritores, Chile (agosto 1969), entre otros.

14 Casa de las Américas, La Habana, Archivo Correspondencia, expediente 224: Carta de Retamar a Arnaldo Orfila, 11/05/1965.

15 Bohemia, La Habana: E. Rodríguez Monegal y R. Fernández Retamar, "Otra vuelta de cuadernos", Año 58, 17, 29/04/1966, p. 8-9; Casa de las Américas: Casa de las Américas, "Carta abierta a Pablo Neruda", 38, septiembre-octubre 1966, p. 131-135.

16 Casa de las Américas: vv.aa., "Declaración de los 20”, 43, julio-agosto 1967, p. 99-101.

17 Aquí quedaría excluido el campo socialista, que consideramos fue invitado por motivos de realpolitik y no fruto de una afinidad político-ideológica o cultural. 
mover visitas de los invitados extranjeros a los centros de investigación, universidades, planes agrícolas e instituciones culturales, tal y como finalmente se hizo ${ }^{18}$. A mayores, se confeccionó un programa de difusión del evento a nivel nacional e internacional ${ }^{19}$. Como puntualizó Gallardo-Saborido (2009: 147), el Congreso era parte de la política exterior cubana: «se tomaban distancias frente a la política cultural de la URSS» y se difundía entre los intelectuales de la Nueva Izquierda «la imagen de una Cuba sin mordazas, en la que la libre expresión estaba permitida».

Se omitiría lo caleidoscópico del contexto previo al Congreso Cultural si atribuyésemos su celebración a una sola causa. Desde la óptica del Gobierno, el Congreso podía representar un espaldarazo de la intelectualidad a la movilización sociopolítica que se fomentaba desde 1965. El aval de figuras de prestigio como algunas de las que acudieron al evento confería legitimidad al liderazgo cubano frente al imperialismo y a los sectores agrupados tras la Unión Soviética. Así, coincidimos con Candiano (2018a: 117) cuando alerta sobre una posible mutilación de la caracterización del evento en caso de no integrar la pretensión cubana de constituir un bloque revolucionario socialista alternativo a Moscú. Pese a todo, es justo reivindicar que, efectivamente, entre la intelectualidad a nivel mundial, aunque con mayor énfasis en el ámbito latinoamericano, se mantenía abierto un debate en torno a su responsabilidad con las luchas de liberación, larvado a inicios de los sesenta, e intensificado en la segunda mitad de la década.

\section{EL SEMINARIO NACIONAL PREPARATORIO}

Entre el 25 de octubre y el 2 de noviembre de 1967 tuvo lugar el Seminario Nacional Preparatorio. Su función fue analizar los temas incluidos en la Agenda General del Congreso Cultural -según el Reglamento (MINCULT, 2015) - y dar a los cubanos una «visión más firme de los problemas» para futuras discusiones (Portuondo, 1979: 156157). Participaron los miembros del Comité Nacional Preparatorio y los intelectuales aceptados por este organismo: en total 1.343 escritores, artistas, científicos y técnicos (CCH, ca. 1967: 68). La organización del Seminario fue similar a la del futuro Congreso. Se crearon cinco comisiones: "Cultura e Independencia Nacional" (I), "La formación integral del hombre" (II), "Responsabilidad del intelectual ante los problemas del mundo subdesarrollado" (III), "Cultura y medios masivos de comunicación" (IV) y "Problemas de la creación artística y del trabajo científico y técnico" (V) ${ }^{20}$.

18 Le Nouvel Observateur: M. Bosquet, "Castro abre un nuevo frente", 24/01/1968; Monthly Review: J. Higgins, "Cuba's Cultural Congress", 19 (10), marzo 1968, p. 21-28. Véase también Salkey (1971).

19 Instituto de Historia de Cuba, La Habana, Archivo Histórico, fondo 10.1, carpeta 51, expediente 9, documento 1238: Informe General referente a la divulgación del Congreso Cultural de La Habana sobre problemas de Asia, África y América Latina, 30/11/1967.

20 Las comisiones estaban dirigidas por un presidente, un vicepresidente y un secretario, cargos ocupados por J. Serguera, M. Cossío y J. A. Portuondo (Comisión I); J. Crombet, J. Mier Febles y J. Aguilera 
Aurelio Alonso confiere gran trascendencia al Seminario por dos razones. Primera, por cuanto se gozó de libertad de expresión: «no se censuró nada, eso fue lo interesante [...] todos dijimos lo que quisimos decir», asegura, estableciendo veladamente una comparación con la libertad de expresión permitida en el Congreso. Y segunda, porque el Seminario posibilitaba un examen crítico del quehacer cultural de la isla, lo cual, puesto en un plano más elevado, contribuía a la categorización del intelectual en un sistema socialista y los modelos posibles para articular la política cultural: «cuando tú dices el exceso de centralismo del Consejo Nacional de Cultura, tú estás criticando una forma de manejar y llevar la política cultural, ¿te das cuenta?» ${ }^{21}$.

El análisis de las ponencias presentadas en el Seminario no refleja homogeneidad; antes bien retrata corrientes dispares en cuanto a la organización de la cultura, las formas y técnicas empleadas en las producciones intelectuales y su proyección hacia las masas. En esta ocasión no podemos detenernos en detalle en todos los contenidos presentados. Nos limitaremos a apuntar algunas de las contradicciones reflejadas, representativas no solo de divergencias frente a la cultura, sino de cortes generacionales y diferentes caminos hacia el socialismo. Cada tendencia buscó imponer su propia visión (Otero, 1999: 115).

$\mathrm{El}$ asunto central de los debates a los que nos referiremos fue el rol del intelectual en la Revolución en relación tanto con su compromiso social como su práctica y sus tareas. En este punto, se manifestó también una corriente antintelectual. El segundo tema de discusión incidió en la relación entre los creadores y las masas. Cerraremos esta lectura con la crítica expresada en el Seminario ante las deficiencias del aparato cultural cubano.

Sobre el papel del intelectual, hubo acuerdo en reafirmar su compromiso social y rechazar una participación apolítica. Existió, asimismo, una aceptación de su implicación como educador de las masas, dadas las carencias de cuadros que tenía la Revolución, y su colaboración en el trabajo manual. Un grupo importante de los presentes consideró que en los países liberados la responsabilidad del intelectual debía revestir la forma de una adhesión crítica ante las problemáticas generadas al interior de la nación. En esta dirección se manifestó, entre otros, J. Yanes ("El caso específico. Cuba dentro del marco de los países subdesarrollados libres”22), quien aclaró que no se debía temer a represalias por parte del Gobierno, pues «había aprendido de los errores ajenos»

Por otro lado, se pudo observar una corriente antintelectual que relativizaba la utilidad de la cultura como arma contra el imperialismo y el subdesarrollo nacional. Como

Maceira (Comisión II); R. Fernández Retamar, W. Torres y A. Fornet (Comisión III); L. Otero, S. Álvarez y E. Desnoes (Comisión IV); y A. Guevara, Z. Marinello y J. Díaz (Comisión V).

21 Entrevista a Aurelio Alonso Tejada, La Habana, 6/12/2018. Alonso dirigió en 1967 la Biblioteca Nacional «José Martí», era miembro del Departamento de Filosofía de la Universidad de La Habana y del Comité de Redacción de la revista Pensamiento Crítico e integró el Comité Nacional Preparatorio del Congreso.

22 Todas las ponencias al Seminario Preparatorio citadas remitirán al siguiente fondo: Casa de las Américas, Archivo Vertical, carpeta Congreso Cultural de La Habana. Seminario Preparatorio, sección Casa y Cultura, inventario C-0575. En algunas de las ponencias no constan datos sobre su autor o título. 
ejemplo, se trae a colación la ponencia que leyó Jorge Valdés Miranda: "Responsabilidad del intelectual ante los problemas del mundo subdesarrollado no liberado". Valdés aclaró que, independientemente de los «kilates artísticos y científicos» de un intelectual, a las masas con hambre no les servían las obras; estas demandaban comer, medicinas, etc. Este enfoque imponía un pensamiento pragmático que subordinaba las producciones intelectuales a la urgencia de las tareas productivas y la militancia política.

Sobre las técnicas y la interacción con el público, en general hubo cierta unanimidad a la hora de no rechazar la experimentación ni los avances logrados en los países extranjeros, siempre y cuando se utilizasen con juicio. Cómo lograr un acceso satisfactorio por parte del pueblo a los productos intelectuales había sido una preocupación latente en los espacios académicos cubanos durante esa década (Martínez Pérez, 2006: 46-66, 263-303). De un lado, se posicionaban los defensores de un «arte claro» en el cual tuviese primacía la comprensión de las masas ${ }^{23}$. Del otro lado y mayoritariamente, se situaron los partidarios de no rebajar la calidad ni el vanguardismo de las obras y potenciar el «ascenso del pueblo»: igual que no había que esperar a que todas las condiciones subjetivas estuviesen creadas para iniciar una revolución, pues el foco podría generarlas, en el campo cultural, creaciones de vanguardia, una labor de búsqueda y una educación adecuada propiciarían también el salto.

Por último, cabe destacar aquellas ponencias enfocadas en deficiencias en el aparato cultural cubano. Los blancos principales de ataque fueron el centralismo de los organismos estatales, las deficiencias materiales y la copia mimética de países extranjeros. Aurelio Alonso puntualiza hoy que el Consejo Nacional de Cultura y la Unión de Escritores y Artistas de Cuba constituyeron dos de las instituciones más cuestionadas por sus limitaciones a la hora de articular la política cultural ${ }^{24}$. Entonces, varias ponencias recogieron el retraso a la hora de incorporar las investigaciones en un marco institucional dinámico, la desvinculación existente entre los organismos culturales y sus miembros, la ausencia de discusión y falta de autonomía -sobre todo en el teatro-, la improvisación a la hora de desarrollar planes, subestimación de las masas en cuanto a su nivel cultural y copia esquemática de métodos de trabajo de otros países desarrollados, fundamentalmente socialistas, sin reparar en las diferencias de hábitos y niveles técnicos.

\section{EL CONGRESO CULTURAL}

El Congreso Cultural se celebró entre el 4 y 12 de enero de 1968. Las actas arrojan un total de 470 delegados procedentes de 65 países, a los que se les sumaron 108 reporteros para informar sobre su evolución. Frente a la idea original de Casa de las Américas, las comitivas fueron eminentemente engrosadas por Occidente: los países desarrollados

23 Defendido, entre otros, por Víctor Agostini en "Ponencia, no; comentario extramuros".

24 Entrevista a Aurelio Alonso Tejada, La Habana, 6/12/2018. 
aportaron 212 delegados, los países subdesarrollados 205, y el bloque socialista $53^{25}$. Si excluimos a los 64 cubanos del total de intelectuales procedentes de los países subdesarrollados el balance resulta aún menos favorable para el tercer mundo.

\begin{tabular}{|l|l|l|l|l|l|}
\hline \multicolumn{2}{|c|}{$\begin{array}{c}\text { PAÍSES DESARROLLADOS } \\
(212)\end{array}$} & \multicolumn{2}{c|}{$\begin{array}{r}\text { PAÍSES SUBDESARROLLADOS } \\
(205)\end{array}$} & \multicolumn{2}{c|}{$\begin{array}{r}\text { BLOQUE SOCIALISTA } \\
(53)\end{array}$} \\
\hline País & Delegados & País & Delegados & País & Delegados \\
\hline Francia & 66 & Cuba & 64 & Rumanía & 12 \\
\hline España & 27 & México & 24 & URSS/Hungría & 9 \\
\hline Italia & 25 & Argentina & 10 & Checoslovaquia & 7 \\
\hline Inglaterra & 22 & Uruguay/RAU & 8 & Bulgaria/Polonia & 5 \\
\hline EE. UU & 21 & Corea & 7 & R.D.A/Mongolia & 3 \\
\hline
\end{tabular}

Figura 1. Desglose de las cinco nacionalidades con más congresistas dentro de cada área geopolítica $\left(\text { n. }{ }^{\circ} \text { delegados }\right)^{26}$

Las únicas invitaciones que fueron cursadas a través de las embajadas, con rango oficial, fueron las del socialismo real (Karol, 1972: 433-438), cuya representación fue encabezada por personalidades pertenecientes a las asociaciones culturales nacionales, escritores y algún miembro de los respectivos Comités Centrales ${ }^{27}$. La República Popular China no participó para no dividir al Congreso ${ }^{28}$.

La lista de invitados se abasteció de las redes intelectuales tejidas a lo largo de la década. Se conocen, por ejemplo, los contactos de Alfredo Guevara con la italiana Rossana Rossanda, el escritor comunista español Ricardo Muñoz Suay y los cineastas Antonio Eceiza y Cesare Zavattini (Guevara y Zavattini, 2002: 182-184; Guevara, 2008: 156-158, 165-168). Carlos Franqui (2006: 325) narró en sus memorias las gestiones que habría resuelto en Europa para la ocasión. Alejo Carpentier habría aprovechado su participación en el Tribunal Russel para divulgar las metas del Congreso ${ }^{29}$. Casa de las Américas había instituido canales comunicativos especialmente importantes en América Latina, gracias en buena medida al premio anual que convocaba (Casañas y Fornet, 1999).

Francia, Estados Unidos, Inglaterra, Italia y España agruparon 161 de los 212 delegados de los países desarrollados. El capital simbólico otorgado a determinadas personalidades de Occidente las hacía especialmente atractivas de cara a la difusión del marco de

25 Recuento a partir de la lista consultada en: Casa de las Américas, Archivo Vertical, carpeta Congreso Cultural de La Habana, sección Casa y Cultura, inventario C-0570.

26 La amplia presencia mexicana se explica por las fluidas relaciones que tenía la intelectualidad cubana con su contraparte. Recordemos que México era el único país de la región que tenía contactos con Cuba.

27 La trayectoria profesional y política de delegados y reporteros se recoge en el informe de la Organización de Estados Americanos sobre el evento (OAS, ca.1968: 31-85).

28 Le Nouvel Observateur: M. Bosquet, "Castro abre un nuevo frente", 24/01/1968.

29 Casa de las Américas: s.a., "Alejo Carpentier a Vietnam y Francia”, 40, febrero 1967, p. 145. 
liberación cubano. El peso de este bloque descansaba sobre un criterio de autoridad y el potencial impacto en la dimensión pública internacional. Para Aurelio Alonso «el criterio de selección a los extranjeros fue a partir de invitaciones de prestigio [...]. Yo pienso que fue un Congreso occidental. Yo también estaba enrolado con eso» ${ }^{30}$.

Como elemento añadido, la estrategia revolucionaria cubana integraba a los sectores progresistas de los países desarrollados, caso del movimiento negro o la intelectualidad crítica con la deriva imperialista y la ortodoxia socialista. Un análisis exhaustivo de la trayectoria profesional y político-ideológica de los invitados sugiere que fueron los sectores adscritos a un pensamiento de Nueva Izquierda los que aportaron una mayor cantidad de delegados, en especial figuras con cierta notoriedad. De Estados Unidos estuvieron Carl Davidson y Todd Gitlin (Students for a Democratic Society, SDS); Robert Fletcher o Jennifer K. Lawson (Student Nonviolent Coordinating Committee, SNCC); Robert Scheer representando a la revista Ramparts, junto con el círculo de la canción protesta (Barbara Dane e Irwin Silber) ${ }^{31}$. Desde Inglaterra acudieron escritores críticos con el comunismo tradicional como Ralph Miliband o Eric Hobsbawm, además de Perry Anderson y Robin Blackburn, editores de New Left Review.

Dentro de la nutrida delegación francesa resaltaron participantes en el Tribunal Russell y antiguos miembros del Partido Comunista Francés firmantes del famoso "Manifiesto de los 121" sobre el derecho a la insumisión de Argelia (1960). A mayores: Alain Geismar, líder del Mayo francés; André Gorz, discípulo de Sartre y escritor en Le Nouvel Observateur y Temps Modernes; Ugné Karvelis de Éditions Gallimard o George Dupré, vinculado en esa década a la revista Partisans y al proyecto editorial de François Maspero. De Italia, acompañando a la ensayista Rossana Rossanda, arribaron los fundadores de dos de las principales casas editoriales de izquierda: Giulio Einaudi y Giangiacomo Feltrinelli. Tampoco faltaron los españoles José Martínez Guerricabeitia y Jorge Semprún en nombre de la editorial Ruedo Ibérico.

Hubo figuras invitadas que no asistieron. Las más destacadas, Jean Paul Sartre, Ernst Fischer, Bertrand Russell y Thiago de Mello, enviaron saludos al evento expresando su solidaridad. Mario Vargas Llosa, Juan Goytisolo o Carlos Fuentes, ausentes por motivos de trabajo, mandaron telegramas de apoyo ${ }^{32}$. Se tiene constancia de invitaciones de Alfredo Guevara al cineasta Glauber Rocha, quien optó por no asistir para evitar represalias que afectasen a sus rodajes (Guevara y Rocha, 2002: 62-64). Louis Althusser, a pesar de recibir más de una invitación para asistir al Congreso, no acudió aduciendo motivos de salud ${ }^{33}$. No obstante, para aquel entonces el francés ya había expresado por

30 Entrevista a Aurelio Alonso Tejada, La Habana, 6/12/2018.

31 Los editores de Monthly Review no fueron, aunque visitarían Cuba en febrero de 1968 (Rojas, 2016: 124).

32 Casa de las Américas, Archivo Correspondencia, expediente 301: Carta de Vargas Llosa a Fernández Retamar, 01/01/1968; expediente 116: Carta de Carlos Fuentes a José Llanusa Gobel, 12/01/1968. 
escrito sus críticas a ¿Revolución en la Revolución? de Régis Debray, un libro que, en última instancia, era una alineación con la estrategia guevarista para tomar el poder ${ }^{34}$. Estas objeciones de Althusser quizás desincentivaron su deseo de viajar. En un artículo sobre el pensamiento de Che Guevara, Néstor Kohan examina las diferencias del argentino con la corriente althussierana. Kohan (1997: 120) propone que en Para leer el capital (1967), al criticar a las corrientes izquierdistas que se habían orientado al humanismo y el historicismo y citar, entre ellas, a los pueblos del tercer mundo que realizaban combates revolucionarios, Althusser aludía al núcleo cubano.

El asunto general del Congreso era "Colonialismo y neocolonialismo en el desarrollo cultural de los pueblos". Las sesiones de trabajo se organizaron en cinco comisiones, cuyas presidencias estaban formadas por delegados del tercer mundo, entre los cuales uno siempre tenía nacionalidad cubana ${ }^{35}$. En las páginas que siguen, recogeremos las ideas generales de cada comisión ${ }^{36}$. La heterogeneidad de países presentes complicaba el enmarcamiento de las problemáticas y un consenso en cuanto a las tareas inmediatas.

La Comisión I se consagró a la "Cultura e independencia nacional”. En líneas generales se perseguía establecer una conexión entre las estructuras políticas, económicas y sociales de los países subdesarrollados con el retraso en la arena cultural, así como indagar en los mecanismos mixtificadores usados por el imperialismo, caso del racismo. La argumentación guardaba relación con la teoría de la dependencia en auge por esos años. Se aplicó el dualismo metrópolis-satélites para explicar el rol de subordinación de los países subdesarrollados en el sistema económico mundial. Las metrópolis nacionales someterían a los centros provinciales del tercer mundo y estos a los locales, reproduciendo el esquema de explotación. Frente a las teorías que argumentaban una pervivencia parcial del sistema feudal, se propuso lo contrario, tal y como señaló Yves Lacoste (Francia, "Reflexiones sobre la originalidad histórica de la situación del subdesarrollo"): «El subdesarrollo no es la supervivencia del pasado, sino el aspecto negativo de lo moderno».

La realidad del subdesarrollo imponía una totalidad colonizada que abarcaba también a las formas políticas e ideológicas. En "Colonialismo y cultura” Fernando Martínez Heredia (Cuba) analizó la desnaturalización e inoperancia que en los pueblos subdesarrollados tenían ciertos aspectos de la democracia: «la caricatura de elecciones periódicas» o «la democracia como utopía reaccionaria de ciertos 'marxistas'». La disyuntiva estaba

34 Casa de las Américas: R. Fernández Retamar, "Presentación a 'Carta de Louis Althusser a propósito de ¿Revolución en la Revolución?’”, 190, enero-marzo 1993.

35 Estaban integradas por J. Serguera (Cuba), C. Nenekhaly (Guinea), A. Cesaire (Martinica), C. Huy Can (Viet Nam del Norte), J. Silva Herzog (México) en la Comisión I; J. Crombet (Cuba), N. Darawche (Siria), R. Matta (Chile) en la Comisión II; Fernández Retamar (Cuba), S. Badian Kouyáte (Mali), J. Cortázar (Argentina), A. Duarte (Guinea Portuguesa) en la Comisión III; L. Otero (Cuba), K. Yong Soun (Corea), K. Phomkong (Laos), T. Dondogín (Mongolia) en la Comisión IV; A. Guevara (Cuba), M. Mouloud (Argelia), H. Tu (Viet Nam del Sur) y J. L. Massera (Uruguay) en la Comisión V.

36 Las referencias a las ponencias del Congreso remitirán a MINCULT (2015). Algunas carecen de título. 
entre la liberación nacional total, esto es, la revolución, o la continuación del subdesarro1lo. Esta propuesta entroncaba con la formulación guevarista relativa a la incapacidad de las burguesías nacionales para liderar un proceso de desarrollo autónomo por su supeditación a las metrópolis. André Gunder Frank (Canadá) tituló sugerentemente su ponencia “¿Quién es el enemigo inmediato?” para referirse al combate contra las burguesías nacionales de los países subdesarrollados (enemigo inmediato) y derrotar así al enemigo estratégico, el imperialismo. De la necesidad de la revolución a la defensa de la lucha armada había un paso que dio el mexicano Alonso Aguilar, entre otros. En "Dependencia, independencia y subdesarrollo" abogaba por asumir que los detentadores del poder «jamás renunciarán gratuita o pacíficamente a sus privilegios, sino a través de la lucha violenta».

La Comisión II versaba sobre "La formación integral del hombre". La pregunta por responder era cómo alcanzar el Hombre Nuevo enunciado por Che Guevara. El pensamiento revolucionario de los sesenta ambicionaba un cambio sincrónico en todas las esferas sociales. Se aprobó reconvertir la visión mercantilista del trabajo bajo el capitalismo a una más humana dentro del socialismo, la puesta en valor de los estímulos morales, la importancia de la educación de las generaciones jóvenes, la eliminación de la barrera divisoria entre trabajo manual e intelectual como factor de concienciación o la liberación de la mujer. Si bien la revolución era una empresa colectiva en el plano social, ella conllevaba un proceso de mutación y verificación en el interior de cada individuo. Como enunció Roberto Matta (Chile), una «guerrilla interior» permitiría la eliminación de «los prejuicios, los intereses creados, la falsa autocrítica».

El inglés David Cooper, adelantando las movilizaciones estudiantiles posteriores, sugirió como medio contrahegemónico la creación de «Centros Revolucionarios de Conciencia»: movimientos espontáneos de autoafirmación autónoma con una planificación mínima. Sólo así se podría romper con la pasividad en los países industrializados, aunque a continuación Cooper aclaraba que en el «segundo mundo» socialista, altamente burocratizado, se perpetuaban formas similares de alienación personal. Precisamente el burocratismo fue tratado en clave comparativa por Robin Blackburn (Inglaterra) y Alexandre Cockburn (Irlanda) en dos ponencias ligadas que contraponían la visión weberiana (arquetipo de burocracia capitalista) y la leninista. Sin aludir a la «Nomenklatura» bajo el estalinismo, señalaban como tránsito al comunismo una burocracia erigida sobre el binomio responsabilidad individual-decisión colectiva.

La Comisión III versó sobre la "Responsabilidad del intelectual ante los problemas del mundo subdesarrollado”. En líneas generales se rechazó el arte puro y se le otorgó a los intelectuales verdaderamente revolucionarios una doble responsabilidad: la de un compromiso ético, en tanto que ciudadanos, que los obligaba a combatir el imperialismo, apoyar las causas de liberación y participar activamente en las tareas de transformación social en aquellos casos en los que triunfase una revolución; y una responsabilidad estética, orientada a la creación, a la renovación constante de las técnicas, los instrumentos metodológicos y las herramientas empleadas. De nuevo, una de las complejidades radicó en el frágil equilibrio entre acción y pensamiento. La jerarquización estratégica de los 
objetivos más inminentes en la lucha contra el imperialismo podía contribuir peligrosamente a un acercamiento a la cultura como actividad periférica en la liberación de los pueblos. Cierta minusvaloración de la producción intelectual pudo verse en algunas ponencias, entre ellas la de Jorge E. Adoum "El intelectual y la clandestinidad de la cultura". En esta se izaba al guerrillero como «símbolo cabal del varón», figura que sobresalía por encima de los intelectuales, presentados por el ecuatoriano como «incompletos, con mal formaciones de la mentalidad o de la conciencia».

Pese a todo, se impuso un afán reivindicativo de la especificidad y la utilidad de la práctica intelectual en relación con la militancia política. Estos dos planos de la realidad social fueron presentados como elementos autónomos, pero orgánicamente unidos en relación con el proceso de transformación social necesario para los países subdesarrollados. Mario Benedetti (Uruguay) en "Sobre las relaciones entre el hombre de acción y el intelectual", si bien apuntó a la trayectoria del Che Guevara como ejemplo para los creadores, no derivó de ello una correlación sistemática entre la etiqueta de intelectual revolucionario y la incorporación a la guerrilla: para el uruguayo este paso ni estaba prohibido ni era obligatorio. Más aún, se cuestionó por qué la intelectualidad debía cargar con más responsabilidad que otros sectores sociales:

\begin{abstract}
Cuando alguien reclama, y no precisamente en sentido metafórico, que el escritor revolucionario debe terminar en soldado o de lo contrario dejar de cumplir su función, uno no tiene más remedio que preguntarse por qué se plantea esa perentoria disyuntiva sólo al escritor, y no al obrero, o al técnico, o al maestro, o al deportista. Esa diferencia de tratamiento puede insensiblemente llevar a la fabricación de una tesis bastante peligrosa. Por ejemplo: que quienes ejercen otros oficios cumplen una necesaria función dentro del ámbito revolucionario, pero que el escritor o el artista sólo asumen, dentro de ese ámbito, un papel de artículos suntuarios..
\end{abstract}

En esta línea se manifestaron diversos delegados. Se consideró que imponer una renuncia a la literatura para dedicarse a la revolución o viceversa representaba una disociación que traslucía el menosprecio por la actividad cultural y la negación de su capacidad de refracción revolucionaria. Hiber Conteris (Uruguay, "El intelectual como intérprete, crítico y transformador de la realidad social") recordó que la actividad intelectual entroncaba con la realidad social y que, dependiendo del carácter que se le imprimiese, esta tendía a consolidar o modificar el proceso histórico-social. Para Conteris, incluso en los países liberados como Cuba, el intelectual podía plantearse que su responsabilidad era el afianzamiento de ciertos valores revolucionarios universales. Sin embargo, esta primera tarea de concienciación nunca podía suponer congelación ni tampoco sustracción a la labor analítica, de búsqueda y creación. De esta forma, se dibujaba al intelectual como constructor de un nuevo ethos hegemónico que combinase, a la par, la insumisión a la dirigencia política.

"Cultura y medios masivos de comunicación" fue la tesis a desarrollar en la Comisión IV. Existió acuerdo en considerar estos medios como mecanismos puestos al servicio 
de una causa, de un ideal, ya fuese este reaccionario o revolucionario, y, por tanto, armas con potencial defensivo o revulsivo de la realidad. Frente al determinismo del marxismo estalinista, las formas ideológicas no fueron consideradas como reflejo de un sistema económico determinado, sino producto de una práctica ideológica orientada a conservar o transformar el orden de cosas existente. Según explicaron los cubanos Marta Pérez, Alberto Batista, Jorge Gómez y Julio Puente ("Radio y televisión: ideología”), sería absurdo pretender ver imparcialidad en una política de radiodifusión, pues siempre hay implícita una producción de ideología, incluso en el proceso de selección de contenidos. Estos medios, explicaban, tenían capacidad para hacer «que se adore o se aborrezca un artista, un producto o un régimen social». Serían, como dijo Edmundo Desnoes, «las armas secretas» que operarían entre la conciencia y la existencia.

Se estableció una diferenciación entre la instrumentalización de los medios de comunicación masiva por las fuerzas imperialistas y las revolucionarias. En el primer caso constituirían canales estabilizadores puestos al servicio de la clase dominante. Actuaban como constructores de la hegemonía cultural necesaria para el mantenimiento del sistema capitalista y encubrían su práctica ideológica tras una fachada de objetividad. En contextos de movilización sociopolítica, los medios de comunicación podían servir como procesos enmarcadores de la acción colectiva y de los objetivos vindicados por las fuerzas revolucionarias. Su éxito como catalizador había sido ya demostrado durante la propia insurrección cubana (Calvo González, 2016). Una vez triunfante la revolución, pasarían a servir como divulgadores de nuevos valores, instrumentos de educación, concienciación ideológica y creación de un consenso al interior del nuevo sistema. En verdad, se trataría de construir una contrahegemonía cultural que destruyese a la anterior, precisamente lo que realizaba Cuba y lo que se pretendía trasladar a escala internacional.

Por último, "Los problemas de la creación artística y del trabajo científico y técnico" se reservaron para la Comisión V, la más heterogénea en cuanto a temáticas y enfoques. En esta sesión se pretendía responder a cómo integrar exitosamente metodología y técnicas modernas en medios con altos índices de analfabetismo y escasez de recursos materiales como eran en su mayoría los de los países subdesarrollados. Se puso el acento en la inoperatividad de los modelos teóricos de los países industriales ante la problemática del tercer mundo y la perentoriedad de emprender campañas masivas de instrucción, se apostó por no rechazar los logros del imperialismo ni tampoco su cultura, sino aprovecharlos desde un posicionamiento crítico y se analizó el fenómeno del «éxodo de talentos» que se sucedía cada año en el sur. Asimismo, se reservó espacio para deliberar acerca de la gestión cultural. Sobre este asunto habló Aurelio Alonso (Cuba) en "Relaciones mercantiles en la cultura". No era novedad afirmar que el mecanismo de selección en la creación artística y literaria capitalistas estaba sometido a las leyes del mercado. Sin embargo, Alonso afirmó que tampoco el socialismo había logrado un proceso eficiente de selección cultural. Dialogando con el marco teórico gramsciano, abogó por una reducción de la función mediadora estatal y la participación del creador y del público en la administración cultural. 
La calidad de las ponencias no contentó a todos los asistentes (Aub, 1969: 44-45, 48). V. Poliakovski reprodujo en un reportaje las quejas soviéticas ante las críticas a la «pérdida de espíritu revolucionario en los países socialistas» ${ }^{37}$. Lamentablemente no existe un registro de las contrarréplicas que pudieron desencadenarse entre el público. Aun así, una ojeada a las intervenciones del Este refleja la poca relación que tenían con el propósito del Congreso. Es ilustrativa la ponencia expuesta por Roman Karmen en la Comisión IV, "La lucha ideológica y los medios modernos de amplia información". Allí el cineasta soviético distinguía dos bandos opuestos: el socialismo y la paz frente al imperialismo y la reacción. El destino de la humanidad se decidía «en esta pugna histórica de dos ideologías», una apreciación que trazaba el mapa geopolítico bajo el esquema de la Guerra Fría, contra el espíritu de Bandung y de la Tricontinental que Cuba promovía.

Otras confrontaciones guardaron relación con la Crisis en el Medio Oriente (Karol, 1972: 436-437). Algunos delegados -sobre todo de la República Árabe Unida y Siriaobjetaron que el imperialismo sionista merecía una condena a la altura del norteamericano. A pesar de que la declaración final del Congreso rechazó la agresión ejercida contra el mundo árabe (CCH, 1968: 54), se tendió a interpretar al sionismo como un enemigo de menor rango en el contexto internacional.

Las resoluciones más relevantes fueron el "Llamamiento de La Habana" y la "Declaración General del Congreso Cultural”. El primer texto había sido originalmente la ponencia del inglés Ralph Miliband a la Comisión I. Testimonios presentes (Salkey, 1971: 217; Karol, 1972: 436-437) apuntan a que cuando este texto fue leído, Miliband habría protestado cortésmente por la inclusión de un pasaje sobre la guerrilla, inexistente en la versión original. Eliminado ese párrafo, fue aprobado. Consta de una página en la que resalta la rebaja del vocabulario militar y la ausencia de referencias a la lucha armada. Se limitaba a propiciar una toma de posición categórica contra la política de colonización cultural estadounidense y «el rechazo de toda invitación, beca, empleo o programa de investigación» que cooperase con esta (CCH, 1968: 46).

La "Declaración General del Congreso Cultural" sintetizaba las principales resoluciones tomadas por cada comisión. En este texto se explicitó la necesaria modificación del marco cultural en la construcción del socialismo. No se trataba únicamente de reorientar el sistema económico y político, sino también de construir nuevos valores colectivos. Si la derrota del imperialismo era diagnosticada como «prerrequisito inevitable» para lograr una cultura genuinamente nacional, el hecho cultural por excelencia era entonces la revolución (CCH, 1968: 56-57). A partir de esta confirmación, se proclamaba la solidaridad militante con todos los pueblos en lucha por su liberación -en un puesto destacado, Vietnam- y el apoyo a la población negra y blanca progresista de Norteamérica.

Más importante, la Declaración evidenciaba un consenso respecto al ensanchamiento de los campos de actuación en los que podía tomar partido la intelectualidad. La enu-

37 Za Rubejom: V. Poliakovski, "Il Congresso della cultura all'Avana" [traducción del francés], 4 (397), 19-25 enero 1968, p. 8-9 (Baldelli, 1969: 393-399). 
meración del amplio abanico de responsabilidades incluía la denuncia, la investigación, la oposición cultural, la desmitificación de las ideologías, la experimentación, la lucha por la lengua nacional y la educación del pueblo. Se le atribuyó a la cultura un carácter subversivo contra el imperialismo. Al fin y al cabo, también los creadores eran hostigados por insertar en sus obras una perspectiva de liberación. Conjuntamente, se abría un horizonte que los ligaba a la problemática de las masas y al inicio o profundización de un proceso revolucionario. El nuevo intelectual debería estar dispuesto a asumir, junto al pueblo, faenas combativas y productivas, la defensa del país y encarar «el riesgo de morir si fuere necesario para que una vida nueva y mejor sea posible» $(\mathrm{CCH}, 1968: 54)$.

Fidel Castro clausuró el Congreso el día 12 de enero de 1968. Citó in extenso la ponencia presentada por cuatro eclesiásticos en la Comisión III: G. Guzmán, Carlos Zaffaroni, Alberto Escardia y P. Blanquart. Recalcó en especial aquellos pasajes que plasmaban un enfoque claramente antimperialista y los señaló como muestra de la emergencia de fenómenos nuevos que obligaban a una reactualización del marxismo:

Tuvo el marxismo geniales pensadores: Carlos Marx, Federico Engels, Lenin, para hablar de sus principales fundadores. Pero necesita el marxismo desarrollarse, salir de cierto anquilosamiento, interpretar con sentido objetivo y científico las realidades de hoy, comportarse como una fuerza revolucionaria y no como una iglesia seudorrevolucionaria [...]. Esperamos, desde luego, que por afirmar estas cosas no se nos aplique el procedimiento de la 'excomunión' (CCH, 1968: 66).

El Comandante alabó enérgicamente el rol jugado por los intelectuales como vanguardia de lucha en determinados países y los encomió por haber demostrado un compromiso mayor que «otras organizaciones de las que se esperaba mayor combatividad» (CCH, 1968: 62). Cierto es que no aludió al bloque del socialismo soviético. Sin embargo, sus juicios dejaban poco margen a la interpretación. La pasividad de la izquierda tradicional y la tan proclamada coexistencia pacífica habían sido el principal nodo en las tensiones entre Cuba y el Este durante los años sesenta. Este discurso no era más que el pico de las divergencias entre dos concepciones diferentes en cuanto a la implementación del socialismo y la conquista del poder. A la vez, con este cierre de Congreso se ratificaba que el Gobierno cubano juzgaría la obra y la actitud de los intelectuales desde un prisma político. La reivindicación que el dirigente hizo de la intelectualidad no se sustentó en la calidad de sus obras, antes bien estaba enraizada en la movilización en favor o en contra de una causa sociopolítica.

\section{CONCLUSIONES}

En el Congreso Cultural confluyeron una variedad de sinergias. Por parte del Gobierno cubano, se veía como positivo el reforzamiento de un frente intelectual que engrosara el proyecto antimperialista aupado desde la isla y que nutriera teóricamente a 
la práctica revolucionaria en curso. A partir de 1965 la dirigencia puso a disposición de las fuerzas revolucionarias de todo el mundo mecanismos relacionales de movilización sociopolítica a través de los cuales incitar a la acción, difundir un imaginario de cambio y dar cuerpo a un movimiento antimperialista que conjugase el ideal de los movimientos de liberación que emergían desde el sur con los sectores progresistas del primer mundo.

Por parte de la intelectualidad, el Congreso abría la posibilidad de reactualizar su compromiso con las causas progresistas, preocupación especialmente presente en América Latina. A este respecto, se observó en la región una preocupación por posicionar a la creación cultural en el marco de la acción sociopolítica. La inminencia de la revolución y las polémicas post-1959 creadas al interior de la izquierda latinoamericana respecto a la estrategia y la táctica para tomar el poder habrían tenido su correlato, aunque en un plano distinto, en el campo intelectual. Esto no quiere decir, por supuesto, que escritores y artistas únicamente teorizaran sobre política y vía armada. Simplemente creemos plausible la hipótesis de que la problematización e interrelación entre acción y pensamiento, con sus significados subyacentes, tuvo en América Latina un protagonismo mayor que en otros contextos geográficos.

La definición que se propuso del intelectual incluía una expansión de sus ámbitos tradicionales de participación. Se proponía una figura que sintetizara las corrientes leninista, gramsciana y revolucionaria cubana. Como ha expuesto Candiano (2018a: 138), las reflexiones en el Congreso Cultural ratificaban un empeño por subvertir la categoría intelectual conjuntamente con la transformación revolucionaria de la sociedad durante los años sesenta. Siempre en línea con el compromiso social, entre las tareas del nuevo hombre intelectual estaría la organización de la cultura, la educación de las masas, la colaboración en el trabajo productivo, la reafirmación y divulgación de una conciencia revolucionaria, el ejercicio de la crítica, la defensa de la liberación de su país, además de experimentar y proyectar los nuevos valores en sus obras a partir de la realidad históricosocial de su tiempo. Una mirada rápida a esta enumeración da buena cuenta de que, para ser merecedor del adjetivo revolucionario, un intelectual debía proyectar esta condición no sólo en su obra, sino en su actitud e intervención social. Mediada la década se produjo un desplazamiento del ideal del compromiso hacia el del intelectual revolucionario, denominación que envolvía precisamente estos dos planos de verificación de su condición: la obra y la vida (Gilman, 2003: 160-161).

La nueva noción del intelectual concedía especial relevancia a la esfera sociopolítica. En la medida en que la lucha contra el imperialismo era el prerrequisito para la construcción de una cultura nacional y para el cambio de las estructuras sociales, la revolución -en clave socialista y armada- pasó a ser el acto que precedía a los demás. Si bien en el Congreso se vindicó el alcance revolucionario que cobijaban las prácticas intelectuales, la expansión de la revolución a nivel mundial y, en el caso cubano, la envergadura del proceso de desarrollo que estaba en curso, fueron factores que paulatinamente contribuyeron a una clasificación de tareas, en cuya cima se colocaron las responsabilidades antimperialistas y los imperativos del avance del socialismo nacional. 
En la isla, tanto la ofensiva revolucionaria lanzada en 1968 - la cual aspiraba a eliminar los vestigios del capitalismo y eliminar los remanentes de propiedad privada en el país- como el descubrimiento de la «microfacción» dentro del partido, contribuyeron a radicalizar a la Revolución. A mayores, tras el Congreso el esfuerzo nacional en la isla se enfocaría en el éxito de la zafra de los 10 millones proyectada para 1970. Estos elementos otorgarían supremacía al frente político y productivo en relación con el pensamiento y alentarían una mentalidad en clave unitaria y defensiva. Como expone Said (1996: 58), en ciertos estados de emergencia y de crisis se instala entre la intelectualidad un sentimiento de lealtad a una causa que consideran justa y equiparan, en ocasiones, cualquier juicio crítico con la traición. Pese a todo y poniéndonos en contexto, coincidimos con Fornet (2013: 69) cuando recuerda que el medio siglo que nos separa de los años sesenta pueden conducirnos, en ocasiones, a descuidar que, realmente, la preocupación más apremiante para la mayoría de la intelectualidad de entonces era la profundización de la Revolución y la liberación nacional.

Respecto a la continuidad que tuvo el ideal emanado del Congreso, dos factores jugaban en contra. En primer lugar y como se ha podido comprobar en las referencias al Seminario Nacional Preparatorio, bajo el aparente monolitismo de la política oficial cubana, coexistían diferentes tendencias sobre la construcción del socialismo, la política cultural y la «claridad» con la que dirigirse a las masas. El segundo factor negativo para el nuevo intelectual era que su desarrollo teórico y su proyección en la práctica social cubana descansaba en el frágil proyecto independiente que el Gobierno había intentado crear desde 1965. En caso de que el balance de fuerzas se viera modificado y el proyecto de socialismo autónomo fracasase, el rol de la cultura en la sociedad también se vería alterado, como se pudo comprobar durante los años setenta (Fornet, 2007, 2013).

En un plano internacional, el discurso de Fidel Castro ante la Primavera de Praga dibujó una nueva línea divisoria. Aunque el dirigente incorporaba en su alegato críticas al socialismo real, es innegable que respaldaba la acción que había emprendido la URSS. Esta demarcación cubana en la arena internacional quebró la imagen de una isla independiente y marcó un primer paso atrás en la relación entre la intelectualidad internacional progresista y el Gobierno cubano. A esto se le añadiría la publicitación hacia noviembre de 1968 de críticas a una supuesta «despolitización» de la literatura nacional ${ }^{38}$ y el inicio del famoso Caso Padilla, episodios que antecederían el cierre de espacios de expresión en la siguiente década (Casal, 1971). Por este motivo, Otero (1999: 116) afirmaría que el Congreso «murió a los siete meses de nacido».

38 Verde Olivo, órgano de las Fuerzas Armadas Revolucionarias, La Habana: L. Ávila, "Sobre algunas corrientes de la crítica y la literatura en Cuba", IX, 47, 24/11/1968, p. 14-18. 


\section{BIBLIOGRAFÍA}

Alburquerque, G. (2011): La Trinchera Letrada. Intelectuales latinoamericanos y Guerra Fría. Santiago de Chile, Ariadna Ediciones. https://doi.org/10.26530/oapen_617569

Acosta, Y. E. (2013): Cuba y la cultura. Primera etapa del proyecto revolucionario internacional: el Salón de Mayo y el Congreso Cultural de La Habana. Tesis de Maestría, Universidad de Salamanca.

Acosta, R. (2015): "El Congreso olvidado", en MINCULT, Ministerio de Cultura, Multimedia Congreso Cultural de La Habana. La Habana, Cubarte.

Artaraz, K. (2011): Cuba y la nueva izquierda: una relación que marcó los años 60. Buenos Aires, Capital Intelectual.

Aub, M. (1969): Enero en Cuba. México, Joaquín Mortiz.

Baldelli, P. (comp.) (1969): Primo Congresso Culturale Dell'Avana. Milán, Del Gallo.

Benedetti, M. (comp.) (1977): Literatura y arte nuevo en Cuba. Barcelona, Laia.

Calvo González, P. (2016): "Percepciones de la Sierra Maestra. La visión de la insurección cubana (1957-1958) a través de los periodistas latinoamericanos", Revista Internacional de historia de la Comunicación, 7, 92-115. https://doi.org/10.12795/ rihc.2016.i07.05

Campuzano, L. (2001): “La revista Casa de las Américas, 1960-1995”, en Fornet, A. y L. Campuzano, La revista Casa de las Américas: un proyecto continental. La Habana: ICIC, 33-70. https://doi.org/10.1353/ntc.1995.0016

Candiano, L. M. (2018a): "El Congreso Cultural de La Habana de 1968. La subversión de la noción de intelectual”, De Raíz Diversa, 5 (10), 113-140. https://doi. org/10.22201/ppela.24487988e.2018.10.67368

Candiano, L. M. (2018b): “1966: intelectualidad en disputa. El debate sobre los 'intelectuales revolucionarios' en Casa de las Américas”, Conflicto Social, 19, 36-70.

Casal, L. (1971): El Caso Padilla: Literatura y Revolución en Cuba. Documentos. Miami, Ediciones Universal.

Casañas, I. y J. Fornet (1999): Premio Casa de las Américas: memoria, 1960-1999. La Habana, Casa de las Américas.

Castro, F. (1968): Discurso pronunciado en la conmemoración del IX Aniversario del triunfo de la Revolución, La Habana, 02/01/1968. Disponible en: <http://www. cuba.cu/gobierno/discursos/1968/esp/f020168e.html> [Consulta: 02/04/2019]

$\mathrm{CCH}$, Congreso Cultural de La Habana (ca. 1967): Reunión de Intelectuales de todo el mundo sobre problemas de Asia, África y América Latina. Seminario Preparatorio. Folleto mimeografiado, s. d.

$\mathrm{CCH}$, Congreso Cultural de La Habana (1968): Reunión de intelectuales de todo el mundo sobre problemas de Asia, África y América Latina. La Habana, Instituto del Libro.

CCPCC, Comité Central del Partido Comunista de Cuba (1968): Informaciones del Comité Central del Partido Comunista de Cuba acerca de las actividades de la microfacción. La Habana, Instituto del Libro. 
CNC, Consejo Nacional de Cultura (1967): Bibliografía para el temario del Congreso Cultural de La Habana, 2 tomos. La Habana, Instituto del Libro.

De la Nuez, I. (2006): Fantasía Roja: los intelectuales de izquierda y la Revolución cubana. Barcelona, Debate.

De la Torre, M. (2008): La política cultural de la Revolución cubana 1971-1988. La Habana, Historia.

Desideri, E. (1968): Documenti della rivoluzione nell'America Latina: $1^{\circ}$ Congresso Culturale Dell'Avana. Risoluzioni e interventi. Milán, Feltrinelli.

Fornet, A. (2007): "El Quinquenio Gris: revisitando el término", Conferencia leída en Casa de las Américas, Ciclo La política cultural del período revolucionario: Memoria y reflexión organizado por el Centro Teórico-Cultural Criterios, La Habana, 30/01/2007. Disponible en: <http://www.debatecultural.net.ve/Observatorio/FornetQuinquenioGris.pdf>

Fornet, J. (2013): El 71. Anatomía de una crisis. La Habana, Letras Cubanas.

Franco, J. (2003): Decadencia y caída de la ciudad letrada: la literatura latinoamericana durante la guerra fría. Madrid, Debate.

Franqui, C. (2006): Cuba, la Revolución: ¿mito o realidad?, memoria de un fantasma socialista. Barcelona, Península.

Gallardo-Saborido, E. (2009): El martillo y el espejo: directrices de la política cultural cubana (1959-1976). Madrid, CSIC.

Gamson, W. A. y D. S. Meyer (1999): "Marcos interpretativos de la oportunidad política”, en McAdam, D., J. M. McCarthy y M. Zald, Movimientos sociales, perspectivas comparadas: oportunidades políticas, estructuras de movilización y marcos interpretativos culturales. Madrid: Istmo, 389-412.

Gilman, C. (2003): Entre la pluma y el fusil: debates y dilemas del escritor revolucionario en América Latina. Buenos Aires, Siglo XXI.

Guevara, A. y G. Rocha (2002): Un sueño compartido. Madrid, Iberoautor.

Guevara, A. y C. Zavattini (2002): Ese diamantino corazón de la verdad. Madrid, Iberoautor.

Guevara, A. (2008): Epistolario. ¿Y si fuera una huella? Madrid, Autor, D.L.

Kalter, C. (2016): The Discovery of the Third World. Decolonization and the Rise of the New Left in France, c. 1950-1976. Cambridge, Cambridge University Press. https:// doi.org/10.1017/cbo9781139696906

Kapcia, A. (2008): Cuba in revolution. A history since the fifties. Londres, Reaktion Books.

Karol, K. (1972): Los guerrilleros en el poder. Itinerario político de la Revolución cubana. Barcelona, Seix Barral.

Katsiaficas, G. (1987): The Imagination of the New Left. A global analysis of 1968. Boston-Mass, South End Press.

Kenny, M. (1995): The first New Left. British Intellectuals after Stalin. Londres, Lawrence $\&$ Wishart. 
Kohan, N. (1997): "El Che Guevara y la filosofía de la praxis", Dialéctica, 31, 117-140. Kruijt, D. (2017): Cuba and revolutionary Latin America: an oral history. Londres, Zed Books Ltd.

Martín Álvarez, A. y E. Rey Tristán (2012): "La oleada revolucionaria latinoamericana contemporánea, 1959-1996. Definición, caracterización y algunas claves para su análisis”, Naveg@mérica. Revista electrónica de la Asociación Española de Americanistas, 9 .

Martínez Pérez, L. (2006): Los hijos de Saturno: intelectuales y Revolución en Cuba. México D. F., FLACSO.

MINCULT, Ministerio de Cultura (2015): Multimedia Congreso Cultural de La Habana. La Habana, Cubarte.

Mudrovcic, M. (1997): Mundo Nuevo: Cultura y guerra fría en la década del '60. Rosario, Viterbo.

OAS, Organization of American States (ca. 1968): Cultural Congress of Havana. Study prepared by the Special Consultative Committee on Security against the subversive action on international communism at its Tenth Regular Meeting. Washington D. C., OAS.

OSPAAAL, Organización de Solidaridad de los Pueblos de Asia, África y América Latina (1966): Primera Conferencia Tricontinental. Documentos y Resoluciones. La Habana, Secretaria General de la OSPAAAL.

Otero, L. (1999): Llover sobre mojado: una reflexión personal de la historia. Madrid, Libertarias.

Pogolotti, G. (2007): Polémicas culturales de los 60. La Habana, Letras Cubanas.

Pogolotti, G. (2011): Dinosauria soy. Memorias. La Habana, Unión.

Portuondo, J. A. (1979): Orden del día. La Habana, UNEAC.

Rojas, R. (2016): Traductores de la utopía: La Revolución cubana y la nueva izquierda de Nueva York. México, Fondo de Cultura Económica.

Said, E. (1996): Representaciones del intelectual. Barcelona, Paidós.

Salkey, A. (1971): Havana Journal. Harmondsworth, Penguin Books.

Silber, I. (ed.) (1968): Voices of National Liberation. The Revolutionary Ideology of the Third World as Expressed by Intellectuals and Artist at the Cultural Congress of Havana. New York, Central Book.

Terán, O. (1993): Nuestros años sesentas. La formación de la nueva izquierda intelectual argentina 1956-1966. Buenos Aires, El Cielo por Asalto.

\section{Fuentes de archivo}

Archivo Vertical y Archivo Correspondencia, Casa de las Américas, La Habana. Archivo Histórico, Instituto de Historia de Cuba, La Habana. 


\section{Fuentes orales}

Entrevista de María Berrios y Jacob Jakobson a Roberto Fernández Retamar, La Habana, abril 2014, recogida en MINCULT (2015).

Entrevista de la autora a Aurelio Alonso Tejada, La Habana, 6/12/2018.

Entrevista de la autora a Roberto Fernández Retamar, La Habana, 28/11/2018. 